\title{
CREAPHIDIDAE, A NEW AND THE OLDEST APHID FAMILY FROM THE TRIASSIC OF MIDDLE ASIA*
}

\author{
By Dmitri E. Shcherbakov and Piotr Wegierek \\ Paleontological Institute, Academy of Sciences \\ Profsoyuznaya 123, Moscow 117321 USSR
}

The only aphid specimen recorded in pre-Jurassic strata is the holotype forewing of Triassoaphis cubitus, which has not been referred to any family (Evans 1956, Heie 1987). Recently, another specimen has been discovered among numerous Triassic Homoptera collected in the rich locality, Dzhailou-Tcho (South Fergana, Middle Asia), and deposited in the Paleontological Institute (Moscow). According to paleobotanical data, the locality is of Ladinian-Carnian age, i.e., roughly synchronous or somewhat older than Carnian Ipswich Group (Dobruskina 1982) that harboured Triassoaphis. The newly found aphid is very primitive and peculiar enough to merit new family status.

\section{Creaphididae, new family}

Diagnosis (fore wing). Pterostigma strongly elongate, tapering, with RS arising from its very base. M 3-branched and slightly curved at base, projecting to the point of $\mathrm{CuA}$-origin. Common stalk of $\mathrm{CuA}$ moderately short; $\mathrm{CuA}$ thicker than $\mathrm{M}$ and distal portion of RS. Arcuate nodal flexion line crosses RS far from its base, and $\mathrm{M}$ close to first fork; convex RS turns concave at nodal line.

Type genus: Creaphis, n.gen.

\section{Creaphis, new genus}

Diagnosis (forewing). Tornus beyond $\mathrm{CuA}$-apex. M-stem subequal to $\mathrm{M}_{3+4}$ and $\mathrm{M}_{1+2}$ to $\mathrm{M} 2$. CuA-stalk as long as about one third of $\mathrm{CuA}_{2}$, the latter about 0.5 of $\mathrm{CuA}_{1}$.

Type species: C. theodora n.sp.

${ }^{*}$ Manuscript received by the editor June 12, 1990. 
Etymology. Creo - produce (Latin), and Aphis.

\section{Creaphis theodora, new species}

Fig. 1

Holotype forewing about $3.0 \mathrm{~mm}$ long and $1.1 \mathrm{~mm}$ wide (proportions may be affected by distortion of silty matrix), membranous, with apex beyond RS. Costal area moderately narrow, with anterior margin arcuate near base. Very thick $\mathrm{R}(+\mathrm{M})$-stem arises from bulbous base, nearly straight at $\mathrm{CuA}$-origin and continues as $R_{1}$ up to level of $M_{2}$-apex. Sc forms deep furrow along $R+M$, becomes weak beyond $\mathrm{CuA}$-origin, diverges from $\mathrm{R}$ at $\mathrm{RS}$-origin, and obliquely enters anterior margin. Pterostigma strongly elongate, almost linear. RS slightly curved at base, convex and relatively thick up to nodal line, concave and thinner beyond it. $M$ thin and concave, emerging close to $\mathrm{R}$ not far from $\mathrm{CuA}$-origin, and, being gently curved, gradually diverges from $\mathrm{R} . \mathrm{M}_{1+2}$-fork triangular, as wide as 0.5 of $\mathrm{M}_{1}$. CuA convex and relatively thick (except $\mathrm{CuA}_{1}$ near apex), both branches diverge from imaginary continuation of stem and gently curve before entering margin. Slender claval furrow distinct almost up to $\mathrm{CuA}_{2}$-apex. Weakly convex, relatively thick Pcu $+1 \mathrm{~A}$, bordering clavus posteriorly, continuing across $\mathrm{CuA}_{2}$-apex as coupling fold. Nodal flexion line passes along $\mathrm{CuA}_{1}$-apex, across $\mathrm{M}$ before first fork and $\mathrm{RS}$ at about $1 / 4$ of its length, and to distal portion of $R_{1}$ (and possibly crosses the pterostigma). Sc+R+M darkened especially at pterostigma, the rest of the forewing uncolored, probably transparent.

Holotype (only specimen known, left fore wing): PIN 2240/3240, part and counter part; Dzhailou-Tcho, $30 \mathrm{~km} \mathrm{~W} \mathrm{Isfara,}$ South Fergana, Middle Asia, USSR; Madygen Fm., Ladinian-Carnian, Middle or Upper Triassic.

Etymology. Theos - God, doreo - give (Greek).

\section{WING MORPHOLOGY OF APHIDS}

Mordvilko (1934) recorded rudimentary $\mathrm{CuP}$ and $\mathrm{Pcu}+1 \mathrm{~A}\left(\mathrm{~A}_{1}\right.$ in his terminology) in forewing as an individual aberration in some recent aphids. According to our observations (Shcherbakov and Wegierek, in prep.), a slight and hardly perceptible (i.e., nonfunc- 

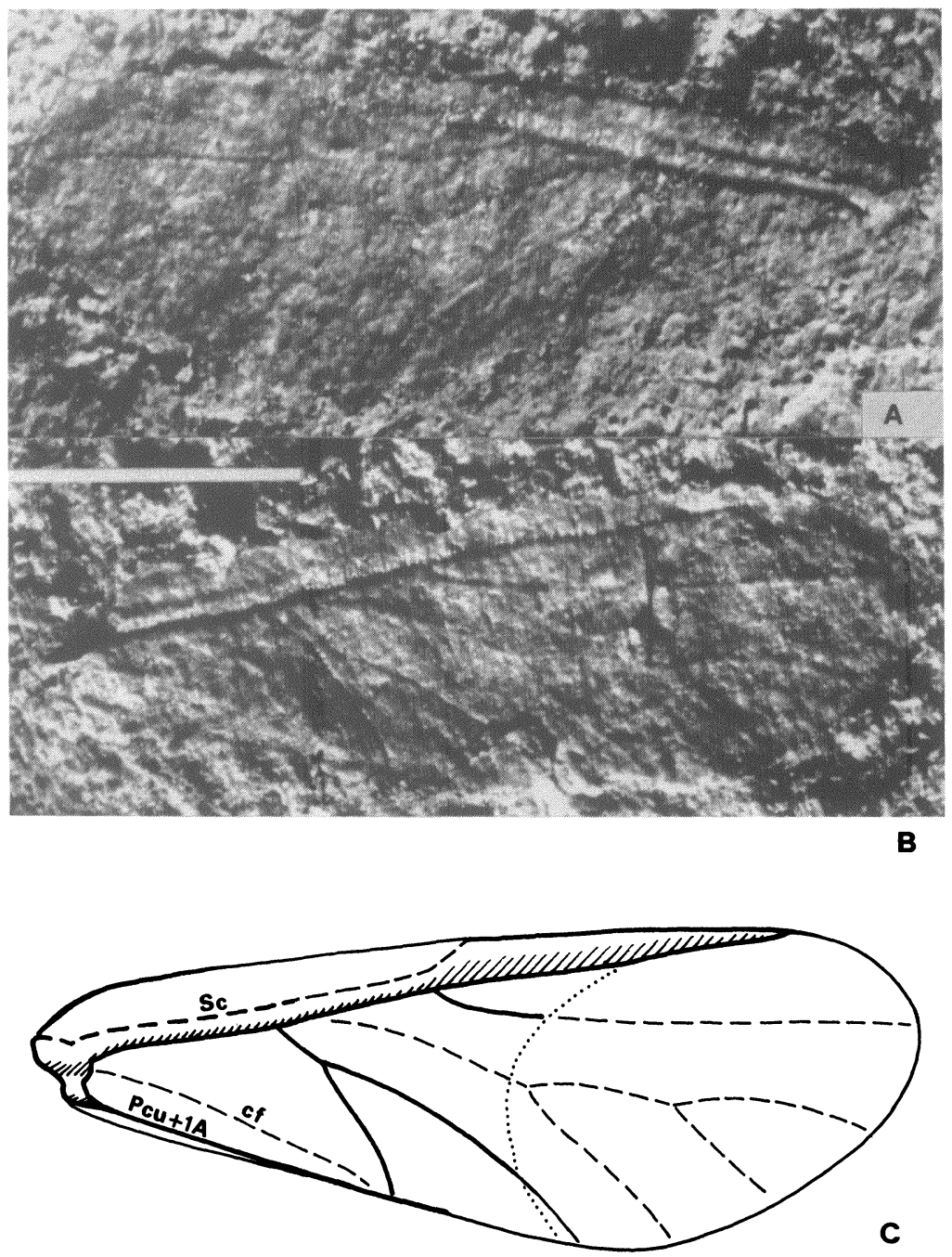

Fig. 1. Creaphis theodora, holotype; forewing, PIN 2240/3240: A, part; B, counterpart. $\mathrm{C}$, venation. Scale bar $=1 \mathrm{~mm}$. Convex veins in continuous line, concave veins in broken line, nodal line in dotted line; cf, claval furrow. 
tional) claval furrow, as well as convex marginal Pcu+1A, is nearly universal among Aphidoidea.

Transverse flexion of forewing along nodal line, a characteristic of some Hemiptera, including ancestral ones (Archescytinidae), and of related orders (e.g., Psocoptera), that occurs also in aphids (Shcherbakov and Wegierek, in prep.). The line observed in fresh specimens of various recent Aphidoidea passes from near $\mathrm{CuA}_{1}{ }^{-}$ apex to the base of pigmented distal portion of $M$ (far from first fork except for Lachnus) and then across either Sc+R (Aphididae, etc.) or pterostigma (its base in Lachnus or distal portion in Prociphilus); in some Mesozoic aphids it evidently passed along posterior margin of pterostigma (Juraphis, Ellinaphis); in all post-Triassic aphids studied it is either straight or angled at $M$ (sometimes ac $\mathrm{Sc}+\mathrm{R}$ ), but never arcuate as in Creaphis and Archescytinidae.

\section{DISCUSSION}

Except for the unique configuration of the nodal line, each diagnostic feature of Creaphididae is shared with some other aphids: RS arising from the base of a very long pterostigma, shared with the Mindaridae; convex basal portion of RS, shared with some Aphidoidea (e.g., Eucallipterus); curved M-base projecting to the point of CuA origin, shared with Schizoneurites obliquus (Elektraphididae, Phylloxeroidea; Heie 1987); short CuA-stalk, shared with some Genaphididae (Juraphis; Shaposhnikov 1979) and Hormaphididae; thicker $\mathrm{CuA}$, shared with Genaphididae, Palaeoaphididae, and Phylloxeridae. These similarities probably reflect some remote relationships of Creaphididae with both Aphidoidea and Phyloxeroidea and somewhat closer relationship with Genaphididae. However, the combination of the above characters in Creaphididae is unique.

The forewing structure of Triassoaphis cubitus, briefly described by Evans (1956) and redescribed on the basis of photographs by Heie (1981), remains incompletely known. As far as visible in the photograph in the latter paper, both Triassic genera are similar in general structure, including shape of pterostigma (correctly figured by Evans), slight claval furrow, and probably also the arculate nodal line (traceable beyond $\mathrm{CuA}_{1}$-apex). However, Triassoaphis is twice as long, with unusually long branches 
of $M$ (not evident in the photograph) and more distal origins of $M$ (close to base of pterostigma) and RS (about midlength of pterostigma, judging from the photograph). The forewing of Triassoaphis, with distal origins of $\mathrm{M}$ and RS, is more costalized (i.e., more derived, Richards 1966) than that of Creaphis. The degree of costalization is rather stable within recent families; thus, we refrain from placing both genera in the same family until the structure of Triassoaphis becomes perfectly known.

\section{SUMMARY}

The second Triassic aphid, Creaphis theodora n.gen., n.sp., representing a new family, Creaphididae, is described on the basis of a forewing from the Middle-Upper Triassic of Middle Asia. The new family is related to the Genaphididae and especially to Triassoaphis, the latter probably representing one more (undescribed) family. A nodal flexion line is reported for the first time in fossil and recent aphids.

\section{Literature Cited}

Dobruskina, I. A.

1982. Triassic floras of Eurasia. Transactions Geol. Inst., 365: 1-196 (in Russian)

Evans, J. W.

1956. Paleozoic and Mesozoic Hemiptera (Insecta). Austral. Journ. Zoology, 4: $165-258$.

HEIE, O. E.

1981. Morphology and phylogeny of some Mesozoic aphids (Insecta, Hemiptera). Ent. Scand. Suppl., 15: 401-415.

1987. Palaeontology and phylogeny. In Aphids, their biology, natural enemies and control. Volume A. Elsevier, Amsterdam e.a.: 367-391.

MORDVILKO, A.

1934. On the evolution of aphids. Archiv. für Naturgesch. N.F., 3: 1-60.

RICHARDS, W. R.

1966. Systematics of fossil aphids from Canadian amber (Homoptera:Aphididae). Canad. Ent., 98: 746-760.

Shaposhnikov, G. Ch.

1979. Descriptions of Mesozoic aphids. Paleontological J., no. 4: 66-78 (in Russian). 

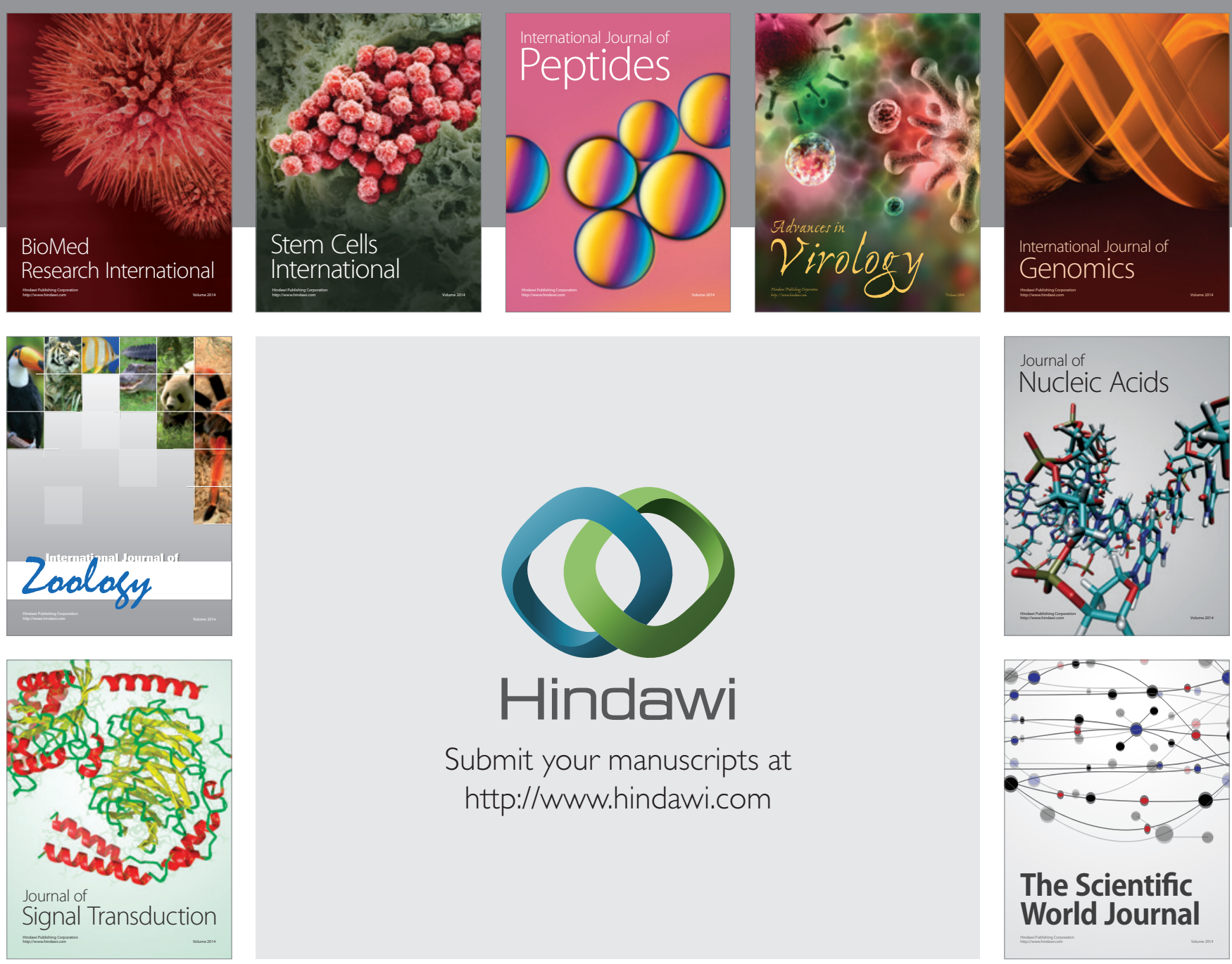

Submit your manuscripts at

http://www.hindawi.com
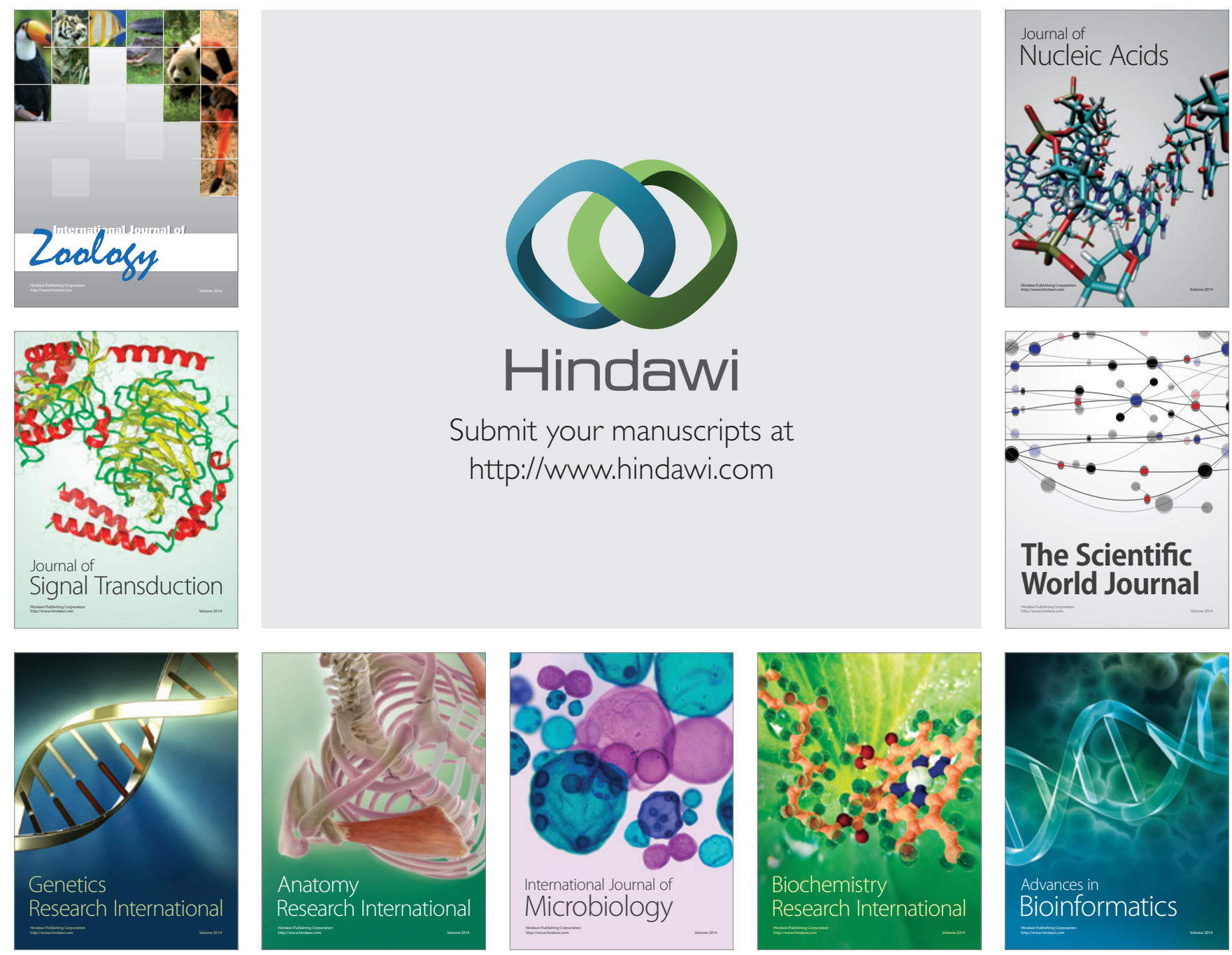

The Scientific World Journal
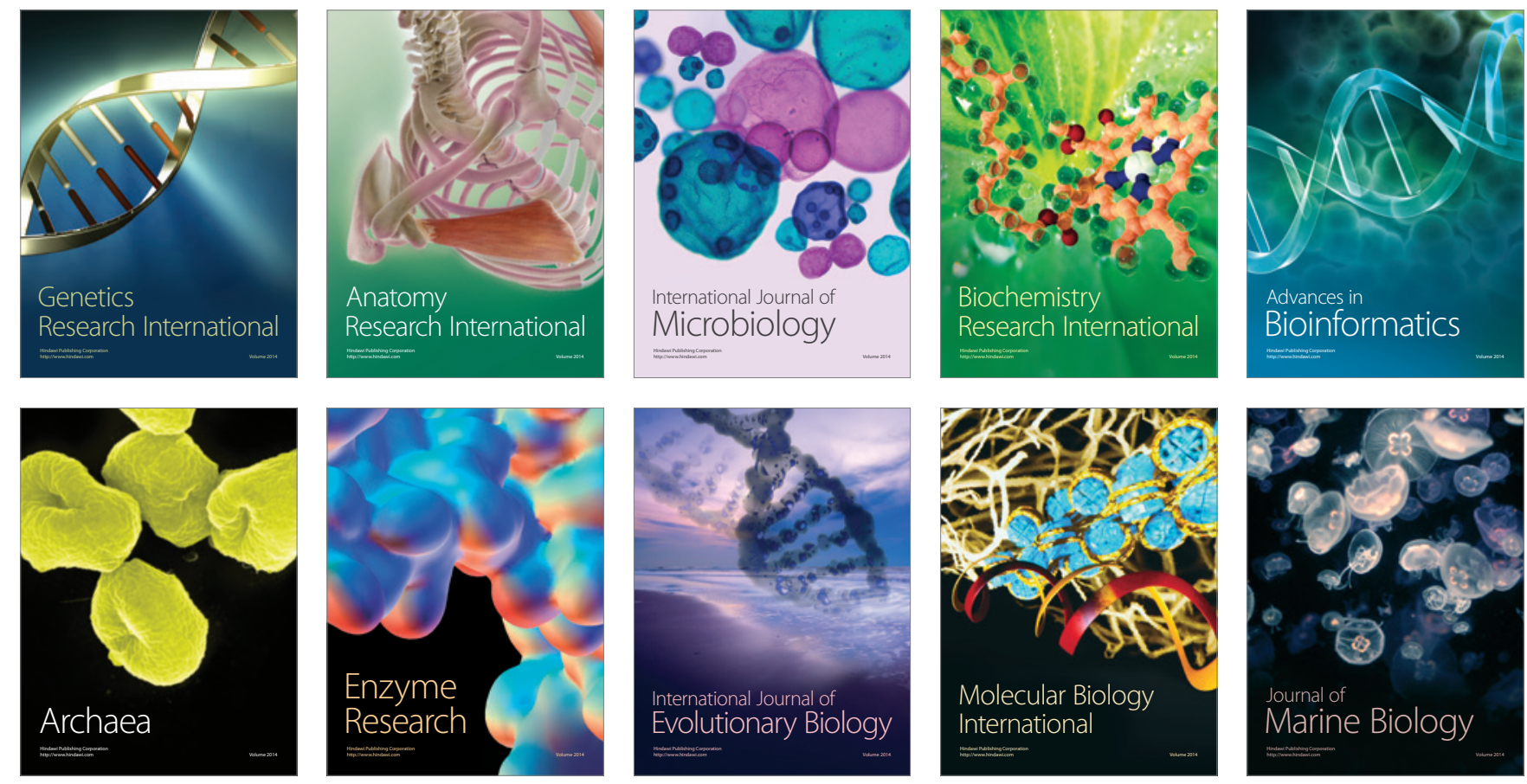